\title{
Role of self-esteem and self-efficacy on competence - A conceptual framework
}

\author{
RAMA L ${ }^{1}$ Dr. Sarada S. ${ }^{2}$ \\ (Research Scholar, School of management studies, Cochin University of science and technology, India) \\ (School of management studies, Cochin University of science and technology, India)
}

\begin{abstract}
This study aims at examining the linkage among self esteem, general self-efficacy and competences of individuals. Attracting competent and motivated people into the organisation is challenging real concerns that make policy makers and researchers think from a diverse range of countries, such as the United States, the Netherlands, Germany, the United Kingdom, Australia and India. Therefore, it is not surprising to observe that a growing body of research examines the underlying reasons for motivating individuals to become effective performers. This study proposes a conceptual model to identify relationship among the variables self-esteem, general self-efficacy and competences.
\end{abstract}

KEYWORDS: Competence, performance, self-esteem and general self-efficacy.

\section{INTRODUCTION}

Globalisation of economy throws a lot of challenges to every industry which penetrates from the top to bottom levels of the management. Of all the challenges managing the work force is the inevitable and the toughest. The changes that take place in the demography and social system have been playing a vital role in renewing the HR practices related to employee productivity, performance and growth. One of the most commonly used HR practice is competency mapping for the development of employees. Identifying and developing the competencies in organisation enable better performance management as well as help the recruitment and selection, training and development, compensation, career and succession planning of the employees and also positions the company in this competitive environment. Competency mapping is a strategic HR framework for monitoring the performance of employees at all levels. Improving the competences of a firm according to the market needs is the most important activity of any organisation in this competitive world. At the back of any superior or successful activity lies a competence. Great leaders in business strategy have identified core competencies, generic competencies that a business firm has to focus to achieve success in all specific environments. Competency mapping is a strategic HR management for monitoring measuring, developing, training, and retaining the powerful human resource in the organisation. In this paper the researcher proposes a conceptual model with the input variables self-esteem, general self-efficacy to understand competences. The existing competencies could be studied in depth to bridge the gap of the lacking competency which help them to get trained and successive planning supporting human resource planning functions in an organisation

\subsection{SELF-EFFICACY}

\section{LITERATURE}

Self-efficacy, defined as "beliefs in one's capabilities to mobilize the motivation, cognitive resources, and courses of action needed to meet given situational demands"(Wood, R., \& Bandura, 1989,p.408). Selfefficacy has been widely studied in organizational behaviour research (Bandura, 1997,Gist, M. E., \& Mitchell, 1992,Stajkovic, A. D., \& Luthans, 1998). Research has established that self -efficacy influences and predicts many other important work-related outcomes and job attitudes,(Saks, 1995),training efficiency(Martocchio, Joseph J., 1997) and job performance and effectiveness (Stajkovic, A. D., \& Luthans, 1998). According to Social cognitive theory (Bandura, 1997,Bandura, 1986), self-efficacy beliefs base on three dimensions (1) level of magnitude i.e., particular level of task difficulty, (2) strength i.e., certainty of successfully performing a particular level of task difficulty and (3) generality i.e., the extent to which magnitude and strength beliefs generalise across tasks and situations Recently researchers have started focussing more on trait -like general dimension of self-efficacy, termed as general self-efficacy (GSC). GSE is defined as “one's belief in one's overall competence to effect requisite performances across a wide variety of achievement situations" (Eden, in press) or as "individuals' perception of their ability to perform across a variety of different situations"(Judge, T. A., Erez, A., \& Bono, 1998).Hence GSE identifies differences among individuals in their feeling to view themselves capable of meeting task demands in a broader range of contexts. Researchers(Judge, T. A., Locke, E. 
A.,\&Durham, 1997,Gardner, D. G., \& Pierce, 1998) have identified that specific self efficacy is a motivational state and general self efficacy is a motivational trait. According to Eden Both GSC and specific self-efficacy (SSE) are beliefs about one's ability to achieve the desired outcomes but the construct differ in scope of application of the performance field. According to Eden,( 1988) GSE is more resistant to ephemeral influences than SSE., GSE and SSE share the same antecedents such as actual experience, vicarious experience, verbal persuasion and psychological states.(Bandura, 1997b).The most powerful antecedent of GSE is the bundle of previous experiences. (Sherer, M.,\&Adams, 1983:Shelton, 1990).Shelton (1990) proposed that GSC evolves over one's life span as an aggregated and accumulated successes and failures across different domains.GSE spreads across different task domains Bandura (1997) stated "Powerful mastery experiences that provide striking testimony to one's capacity to effect personal changes can also produce a transformational restructuring of efficacy beliefs that is manifested across diverse realms of functioning. Such personal triumphs serve as transforming experiences. What generalizes is the belief that one can mobilize whatever effort it takes to succeed in different undertakings". (p. 53) GSC contributes to accumulated successes, persistent positive vicarious experiences, verbal persuasion and psychological states in an individual. According to Judge et.al (1997), GSE relates to other self-evaluation constructs, including self-esteem, locus of control and neuroticism. Judge and colleagues have identified high correlations between GSE and self- esteem.(Judge, T. A., Bono, J. A.,\&Locke, 2000).Chen, Gully and Eden have established that GSE is positively associated to need achievement and conscientiousness other motivational traits.(Chen, G., Gully, S.M., \& Eden, 2001). GSE positively influences SSE across tasks and situations, especially to make an individual feel more efficacious across tasks and situations is the power and influence of GSE.(Eden, 2001)Bandura (1997) claimed that GSE measures "bear little or no relation either to efficacy beliefs related to particular activity domains [i.e., SSE] or to behavior" (p. 42).(Bandura, 1997). General self-efficacy (GSE) is the belief in one's competence to tackle novel tasks and to cope with adversity in a broad range of stressful or challenging encounters, as opposed to specific self-efficacy, which is constrained to a particular task at hand. This study based on social-cognitive theory of Bandura explores relations between GSE and the other psychological constructs from seven countries among 8796 respondents. A high positive association found between GSE and optimism, self-esteem and self-regulation. A negative association found between GSE and depression and anxiety.(Luszczynska, Gutiérrez- Doña, \& Schwarzer, 2005)Self efficacy is defined as a quality that is effective in behaviours and individual's self judgment about himself regarding the capacity to organize necessary thing to carry out a performance and do it successfully (Bandura, 1997). Self efficacy has been explained as individual's expectations about himself regarding level of success when he faces a new situation (Tschannen-Moren and Woolfolk Hoy, 2001), student's level of success and ability to teach about positive behaviours occurring from behaviours (Kiremit, 2006)

\subsection{SELF-ESTEEM}

Morris Rosenberg (1965) and Social-learning theorists defined self-esteem in terms of a stable sense of personal worth or worthiness, measurable by self report testing. Nathaniel Branden (Branden, 1992) defined self-esteem as "the disposition of experiencing oneself as competent in coping with the basic challenges of life and as being worthy of happiness". This two-factor approach provides a balanced definition that seems to be capable of dealing with limits of defining Self-esteem primarily in terms of competence or worth alone. There are two components to Branden's definition. The first he calls self-efficacy: "confidence in the functioning of my mind, in my ability to think, understand, learn, choose, and make decisions; confidence in my ability to understand the facts of reality that fall within the sphere of my interests and needs; self-trust, self-reliance". The second is self-respect: "Self-respect means assurance of my value; an affirmative attitude towards my right to live and be happy; comfort in appropriately asserting my thoughts, wants and needs; the feeling that joy and fulfilment are my natural birthright". Branden's (1992) description of self esteem includes the following primary properties:

- Self-esteem as a basic human need.

- Self-esteem as an automatic and inevitable consequence of the sum of individuals' choices in using their consciousness.

- Something experienced as a part of, or background to, all of the individual's thoughts, feelings and actions.

In his famous book, 'The power of self-esteem' Nathaniel Branden (1992) remarks that "self-esteem is the experience that we are appropriate to life and to the requirements of life. More specifically, self-esteem is :

1. Confidence in our ability to think and to cope with the basic challenges of life.

2. Confidence In our right to be happy, the feeling of being worthy, deserving, entitled to assert our needs and wants and to enjoy the fruits of our efforts".

According to Blascovich, J., \& Tomaka,( 1991) self-esteem refers to an individual's sense of his or her value or worth, or the extent to which a person values, approves of, appreciates, prizes, or likes him or herself. Branden 
points that "positive self-esteem is the immune system of the spirit, helping an individual face life problems and bounce back from adversity".(Branden, 1992)

"Self-esteem is how we value ourselves; it is how we perceive our value to the world and how valuable we think we are to others. Self-esteem affects our trust in others, our relationships, and our work - nearly every part of our lives. Positive self-esteem gives us the strength and flexibility to take charge of our lives and grow from our mistakes without the fear of rejection.

The outward signs of positive self-esteem:

- Confidence

- Self-direction

- Non-blaming behaviour

- An awareness of personal strengths

- An ability to make mistakes and learn from them

- An ability to accept mistakes from others

- Optimism

- An ability to solve problems

- An independent and cooperative attitude

- Feeling comfortable with a wide range of emotions

- An ability to trust others

- A good sense of personal limitations

- Good self-care

- The ability to say no

Low self-esteem is a debilitating condition that keeps individuals from realizing their full potential. A person feels unworthy, incapable, and incompetent to live if he possess low self-esteem. In fact, because the person with low self-esteem feels so poorly about him or herself, these feelings may actually cause the person's continued low self-esteem.

The signs of low self-esteem:

- Negative view of life

- Perfectionist attitude

- Mistrusting others - even those who show signs of affection

- Blaming behavior

- Fear of taking risks

- Feelings of being unloved and unlovable

- Dependence - letting others make decisions

- Fear of being ridiculed"

There are various studies found in literature which links the concept of self esteem to motivation, performance, stress, workplace, outcome, happiness, mental well being, competence and leadership of individuals and teams in an organization. This study relates the linkages between self esteem and teacher competence. Only competent individuals result in superior work performance and job effectiveness. High level of self esteem always relates to positive superior performance in the organization settings and vice versa.(Korman, 1970). Individuals who are more adaptive to the situational needs behave according to the feedbacks of the work setup, possess low self esteem. These individuals think and feel what others think about them.(Brockner, 1988) Researchers had established mixed results supporting direct and indirect relationships between self esteem and job performance. (Carson, K. D., Carson, P. P., Lanford, H., \& Roe, 1997, Strauss, 2005,Erez, A., \& Judge, 2001,Gardner, D. G., $\&$ Pierce, 1998). The survey results of 40 studies were collated by Judge and Bono which consisted of 5000 participants established a weak positive relationship between self esteem and performance. Competence is the threshold of job performance and job effectiveness. In the teacher context, very few studies have been found with reference to teacher competence in higher education. This chapter gives some important glimpses and findings from review of literature reporting the linkage between self esteem and teacher competence of individuals directly or indirectly.( Bono, J. E., \& Judge, 2003) Individuals who score on low self esteem always depend on others approving them on the positive note. They are more influenced by external fluctuations, low degree of interpersonal relationships. The most important research finding is that the low self esteemed individuals can be trained to reach the high score on self esteem in their lives, so that they are benefitted to enhance their self concept through training interventions.(Robbins, 2001)

\subsection{COMPETENCE}

Competence was first introduced and assessed by McClelland in 1970s, competencies, or individual characteristics, are identified as predictors of employee successful performance. Equal importance was given for individual's academic aptitude ,knowledge and skill content .(McClelland, 1973,Schley, D. G., Lucia, A. D., \& Lepsinger, 1999). A competency is a capability of applying knowledge, skills, abilities, behaviours, and 
personal characteristics to successfully perform critical work task, specific functions, or operate in a given role or position. The attributes of personal characteristics are mental, intellectual, cognitive, social, emotional, attitudinal, physical and psychomotor attributes necessary to perform.(Boyatzis, 1982,Dubois 1993.Schley, D. G., Lucia, A. D., \& Lepsinger, 1999). Boyatis (1982) and Fogg (1999) Included both internal and external constraints, environments and relationships related to occupation. In short competences are specific personal qualities that are "causally relates to effective / superior performance" (Boyatis 1982). According to the authors (Verma, Sarita and Paterson, Margo and Medves, 2006) "competencies in education create an environment that fosters empowerment, accountability, and performance evaluation, which is consistent and equitable. The acquisition of competencies can be through talent, experience, or training." Barr (1998) gives the following examples of collaborative competencies: "Describe one's roles and responsibilities clearly to other professions. Recognize and observe the constraints of one's role, responsibilities and competence, yet perceive needs in a wider framework. Recognize and respect the roles, responsibilities and competence of other professions in relation to one's own. Work with other professions to effect change and resolve conflict in the provision of care and treatment. Work with others to assess, plan, provide and review care for individual patients. Tolerate differences understandings and shortcomings in other professions. Facilitate inter-professional case conferences, team meetings,"

\subsubsection{What is competency?}

A competency is an underlying characteristic of an individual that is related to effective performance in a job or situation.

Competency: A person-related concept that refers to the dimension of behaviour lying behind competent performer.

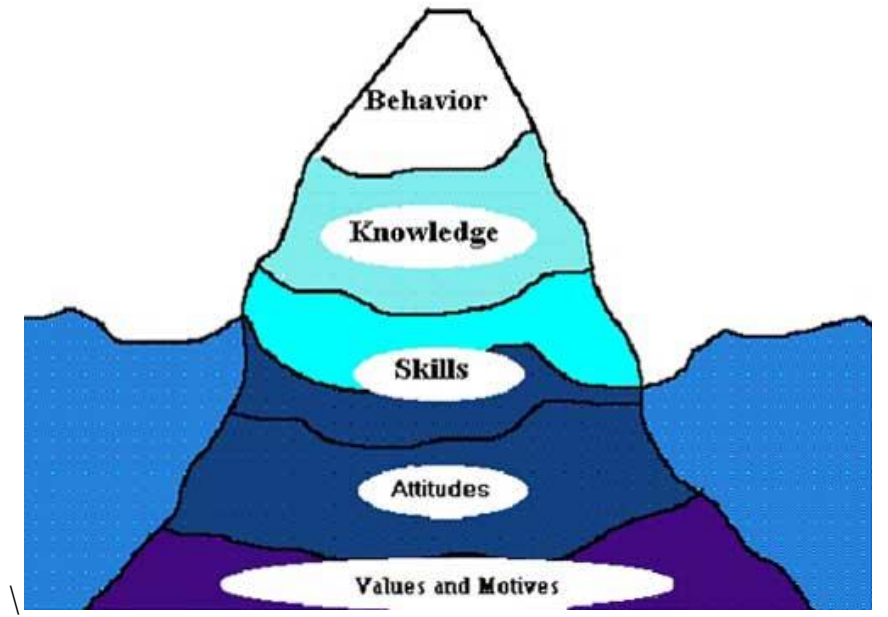

Central and Surface Competencies-Iceberg Model

Source: Spencer, L. M. JR. \& Spencer, S. M., Competence at Work: Model for Superior Performance, John Wiley \& Sons.

Competencies include the collection of success factors necessary for achieving important results in a specific job or work role in a particular organization. Success factors are combinations of knowledge, skills, and attributes (referred as "KSA's") those are described in terms of specific behaviours, and are demonstrated by superior performers in those jobs or work roles. Attributes include personal characteristics, traits, motives, values or ways of thinking that impact an individual's behaviour. Competence is a standard requirement for an individual to properly perform a specific job. It consists of knowledge, skills and behaviour used in such a way to improve performance. In general, competence is the state or quality of being adequately or well qualified, having the ability to perform a specific role. Management competency includes the traits of systems thinking and emotional intelligence, and skills in influence and negotiation. A person possesses a competence as long as the skills, abilities, and knowledge that constitute that competence are a part of them, enabling the person to perform effective action within a certain workplace environment. The competencies have five characteristics, they are

Motives: Things a person consistently thinks about or wants that cause action, motives drive, direct and select behaviour towards certain actions. Traits: Physical characteristics and consistent responses to situations. Self Concept: A person's attitude value or self image. Knowledge: Information a person has in a specific work area Skill: The ability to perform certain mental or physical tasks. The four general competences are relation competence, learning competence and change competence. 
Types of Competencies

1. Organizational competencies - unique factors that make an organization competitive

2. Job/Role competencies - things an individual must demonstrate to be effective in a job, role, function, task, or duty, an organizational level, or in the entire organization.

3. Personal competencies - aspects of an individual that imply a level of skill, achievement, or output

\subsubsection{Managerial Competency}

Competencies are considered essential for staff with managerial responsibility in any service or program area, including directors and senior posts. Some managerial competencies could be more relevant for specific occupations, however they are applied horizontally across the Organization, i.e. analysis and decisionmaking, team leadership, change management, etc.

\subsubsection{Generic Competencies}

Competencies are considered essential for all staff, regardless of their function or level, i.e. communication, program execution, processing tools, linguistic, etc.

\subsubsection{Technical/Functional Competencies}

Specific competencies which are considered essential to perform any job in the Organization within a defined technical or functional area of work, i.e. environmental management, industrial process sectors, investment management, finance and administration, human resource management, etc.

\subsubsection{Competency Mapping}

Competency mapping is the process of identifying the key in an individual that are the most critical to succeed in a work role or situation. It also identifies the key competencies for a particular position in an organisation and then and then using it for job-evaluation, recruitment, training and development, performance management, succession planning etc., Success of any organisation depends on identifying its strengths and weakness. Competency mapping is a process through which one assesses and determines one's strengths as an individual worker and in some cases, as part of an organization. It generally examines two areas emotional intelligence or emotional quotient (EQ), and strengths of the individual in areas like team structure, leadership, and decision-making. Large organizations frequently employ some form of competency mapping to understand how to most effectively employ the competencies of strengths of workers. They may also use competency mapping to analyze the combination of strengths in different workers to produce the most effective teams and the highest quality work. Effectiveness for an organisation is the summation of the competencies such as gap analysis, role clarity, selection, potential identification growth plans, succession planning, restructuring and inventory of competitions for future planning.

\section{CONCEPTUAL FRAME WORK}

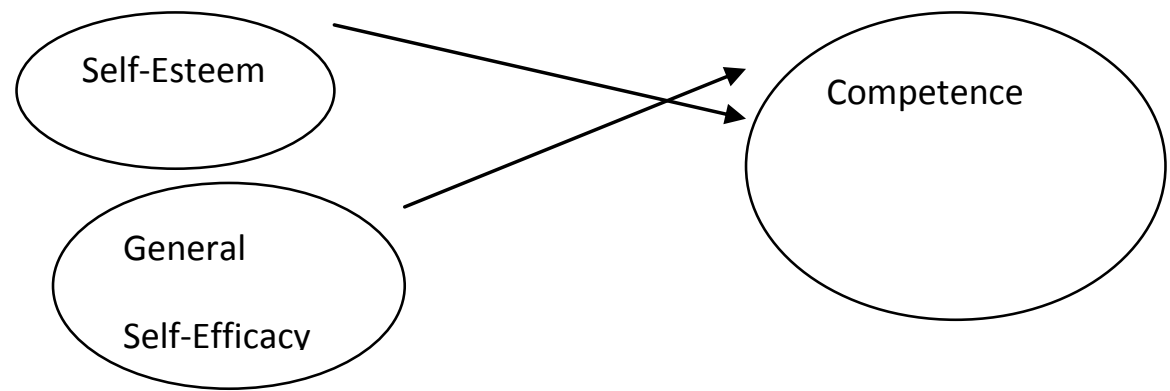

The following are the proposed objectives

1) To study the relationship between competence and self esteem.

2) To study the relationship between competence and general self efficacy.

3) To study the relationship between self esteem and general self efficacy.

\section{DISCUSSIONS}

From the above literature its evident that self-esteem and general self-efficacy are very important input variables for competence which is the threshold of performance. The literature showed the importance of selfesteem and general self-efficacy in an individual which are directly connected with superior performance hence linked with competence of the individual. From the literature it is so evident that the relationship between selfesteem with competence and general self-efficacy with competence are not found which throws gap for further research to be done in establishing these relationships. Hence general self efficacy is linked to all the human 
functioning domains in literature. Hence becomes very important input aspect to study competence in an individual. Similarly self-esteem also proves the self worthiness of an individual which is also linked with positive aspects to enhance competence. Hence self-esteem and general self-efficacy determines competence and enhances performance in an individual. This study becomes very important to academic view point and practical aspects. This would help the human resource department to undertake training programmes to enhance general self-efficacy and self-esteem to train the individuals to become more competent in their domains through development activities. This study further helps in mapping competencies for the job specific domains and levels. High general self-efficacy and self-esteem drives a person to become competent to result in remarkable performance.

\section{CONCLUSIONS}

This study helps in understanding different dimensions of competence of employees in an organisation. It may help in involving appropriate selection process of employees. It may provide more awareness regarding career competence which leads to career growth. It may be possible to set performance standards for the employees. It may enhance the competitive position in the quality of organisation. The competence framework applied in organisation may help linkage between employee development and human resource management. Understanding competence helps in improving the performance standards of the employees and hence increases the competitive position of the organisation in the market. This also helps in retaining the superior performers who are a real asset to any organisation. Moreover this study helps in competency mapping which is a dire need in this present times for any organisation. Identifying the competencies of a job enhances the values for the organisation. Competency profiling helps in identifying the superior performers and hence helps in training the other below average employees in an organisation. This helps in training and successive planning at the organisation level. This study helps for mapping identified competencies for training and successive planning in human resource functions of an organisation.

\section{REFERENCE}

[1] Wood, R., \& Bandura, A. (1989). (1989). Impact of conceptions of ability on self-regulatory mechanisms and complex decision making. Journal of Personality and Social Psychology, 56(3), 407., 56(3), 407.

[2] Bandura, A. (1997). (1997b). Self-efficacy: The exercise of control.

[3] Gist, M. E., \& Mitchell, T. R. (1992). Self-efficacy: A theoretical analysis of its determinants and malleability. Academy of Management Review, 17(2), 183-211.

[4] Saks, A. M. (1995). Longitudinal field investigation of the moderating and mediating effects of selfefficacy on the relationship between training and newcomer adjustment. Journal of Applied Psychology, 80(2), 211., 80(2), 211.

[5] Martocchio, Joseph J., and T. A. J. (1997). Relationship between conscientiousness and learning in employee training: mediating influences of self-deception and self-efficacy. " Journal of Applied Psychology, 82(5), 764.

[6] Stajkovic, A. D., \& Luthans, F. (1998). Self-efficacy and work-related performance A meta-analysis. Psychological Bulletin, 124(2), 240.

[7] Bandura, A. (1986). Social foundations of thought and action: A social cognitive theory. Englewood Cliffs, NJ: Prentice Hal

[8] Judge, T. A., Erez, A., \& Bono, J. E. (1998). The power of being positive: The relation between positive self-concept and job performance. Human Performance, 11(2-3), 167-187., 11(2-3), 167-187.

[9] Judge, T. A., Locke, E. A.,\&Durham, C. C. (1997). The dispositional causes of job satisfaction: A core evaluations approach. Research in Organizational Behavior, 19, 151-188.

[10] Eden, D. (1988). Pygmalion, goal setting, and expectancy: Compatible ways to raise productivity. Academy of Management Review, 13, 639-652., 13, 639-652.

[11] Sherer, M.,\&Adams, C. H. (1983). Construct validation of the Self-Efficacy Scale. Psychological Reports, 53, 899-902.

[12] Shelton, S. H. (1990). Developing the construct of general self-efficacy. Psychological Reports, 66, 987994

[13] Judge, T. A., Bono, J. A.,\&Locke, E. A. (2000). Personality and job satisfaction: The mediating role of job characteristics. Journal of Applied Psychology, 85, 237-249.

[14] Tschannen-Moran, Megan and Hoy, A. W. (2001). Teacher efficacy: Capturing an elusive construct. Teaching and Teacher Education, 17(7), 783-805.

[15] Kiremit, H. (2006). Preservice science teachers' self efficacy beliefs in teaching biology. Unpublished Master Thesis), ^.I\}zmir: Dokuz Eyl\{"ull University.

[16] Rosenberg, M. (1965). Society and the adolescent self-image. Princeton, NJ: Princeton university press. (Vol. 11). 
[17] Branden, N. (1992). Power of Self Esteem. Barnes $\backslash \&$ Noble Books.

[18] Blascovich, J., \& Tomaka, J. (1991). Measures of self-esteem. Measures of Personality and Social Psychological Attitudes, 1, 115-160., 1, 115-160.

[19] Korman, A. K. (1970). Toward an hypothesis of work behavior. Journal of Applied Psychology, 54(1p1), 31.

[20] arson, K. D., Carson, P. P., Lanford, H., \& Roe, C. W. (1997). The effects of organization-based selfesteem on workplace outcomes: An examination of emergency medical technicians. Public Personnel Management, 26(1), 139-155.

[21] Strauss, J. P. (2005). Multi-source perspectives of self-esteem, performance ratings, and source agreement. Journal of Managerial Psychology, 20(6), 464-482.

[22] Erez, A., \& Judge, T. A. (2001). Relationship of core self-evaluations to goal setting, motivation, and performance. Journal of Applied Psychology, 86(6), 1270-1279.

[23] Bono, J. E., \& Judge, T. A. (2003). Core self-evaluations: A review of the trait and its role in job satisfaction and job performance. European Journal of Personality, 17(S1), S5-S8.

[24] Robbins, S. P. (2001). Organizational behavior, (14th ed.). Pearson Education India.

[25] McClelland, D. . (1973). Testing for competence rather than for "intelligence". The American Psychologist, 28(1), 1-14. https://doi.org/10.1037/h0038240

[26] Boyatzis, R. E. (1982). The competent manager: A model for effective performance. John Wiley $\backslash \&$ Sons.

[27] Dubois, D. D. (1993). Competency-Based Performance Improvement: A Strategy for Organizational Change. ERIC.

[28] Schley, D. G., Lucia, A. D., \& Lepsinger, R. (1999). The art and science of competency models: Pinpointing critical success factors in organizations. jstor.

[29] Fogg, C. D. (1999). Implementing your strategic plan: How to turn "intent” into effective action for sustainable change. AMACOM Div American Mgmt Assn.

[30] Verma, Sarita and Paterson, Margo and Medves, J. (2006). Core competencies for health care professionals: what medicine, nursing, occupational therapy, and physiotherapy share. Journal of Allied Health, 35(2), 109-115.

[31] Barr, H. (1998). Competent to collaborate: towards a competency-based model for interprofessional education. Journal of Interprofessional Care, 12(2), 181-187. 